\title{
Crianças Autistas e o Processo de Ensino e Aprendizagem: desafio para Pais e Professores
}

\author{
Cicera Reuva da Silva Carvalho ${ }^{1}$
}

\begin{abstract}
Resumo: Quando se fala sobre autismo, percebe-se que são muitas as dúvidas e indagações a serem respondidas sobre o referido tema. Neste contexto fica difícil identificar as características de uma criança com autismo. No âmbito escolar há um grande desafio para se lidar com esse transtorno, tornando assim mais difícil a identificação e o acompanhamento junto a clientela. O papel do psicopedagogo nesse processo de acompanhamento e adaptação da criança autista é primordial e de grande importância para a família, pois proporciona uma melhor comunicação entre pais e filhos com Transtorno do Espectro Autista (TEA. O objetivo do presente estudo foi identificar as dificuldades encontradas tanto pela família como pelos professores que trabalham com as crianças autistas. A metodologia usada foi a qualitativa, através de uma visita a uma Associação de Pais e Amigos dos Excepcionais (APAE). Foi utilizado um questionário com a psicopedagoga e com a profissional que faz o atendimento as crianças com autismo.
\end{abstract}

Palavras - Chave: Criança autista, Processo ensino - aprendizagem, Métodos.

\section{Children with Autism and the teaching and Learning Process: challenge for Parents and Teachers}

\begin{abstract}
When talking about autism, it is clear that there are many doubts and questions to be answered about the said topic. In this context it is difficult to identify the characteristics of a child with autism. In the school environment there is a big challenge to deal with this disorder, making it more difficult to identify and follow up with the customer.The role of the educational psychologist that monitoring and adaptation of autistic children process is essential and of great importance to the family as it provides better communication between parents and children with autism spectrum disorder (ASD). The aim of this study was to identify the difficulties encountered both the family and the teachers who work with autistic children. The metodology used was qualitative, through a visit to the Association of Parents and Friends of Exceptional children (APAE). A questionnaire has been used with the educational psychologist and the professional who makes care children with autism.
\end{abstract}

Keywords: Autism Child, The teaching-learning process, methods.

\section{Introdução}

Quando se ouve falar sobre autismo, pensa-se logo em uma criança que nasce com algum retardo mental ou mesmo uma criança egocêntrica, principalmente se tratando de primogênito, que no momento é uma exclusividade para os pais, pois estas brincam de forma isolada e são pouco comunicativas, pelo fato de não terem com quem brincar, ao mesmo tempo querem atenção exclusiva.

\footnotetext{
${ }^{1}$ Cicera Reuva da Silva Carvalho, reuvasilva@ gmail.com, Mestranda pela Anne Sullinvan University, Especialização em Psicopedagogia
} pela Faculdade de Juazeiro do Norte - FJN Graduada em Pedagogia pela Universidade Regional do Cariri. E-mail: reuvasilva@ gmail.com. 
É comum no contexto escolar, constatar a presença de pessoas que lidam diretamente com crianças autistas. São professores e pais que uma vez envolvidos no processo de ensino aprendizagem, vivenciam dificuldades que impossibilitam o bom desenvolvimento do processo de ensino e aprendizagem, e que por vezes os deixam com dúvidas e receios.

Há, portanto, necessidade de conhecer as características do autismo, entender o comportamento de crianças autistas, e capacitar-se a lidar diretamente com esta diferença.

Diante deste contexto permeado por desafios, surgiram os seguintes questionamentos: Quais dificuldades são encontradas pela família e por professores, para lidarem com crianças autistas em relação ao processo de ensino e aprendizagem? Estão as escolas da rede pública de ensino, preparadas e equipadas para desenvolverem o trabalho específico com crianças/alunos autistas?

Percebe-se que são muitas as dúvidas e indagações a serem respondidas quando se discute o tema autismo. Sabe-se que existe uma série de estudos sobre o assunto, além de instruções específicas emanadas da Secretaria de Educação Especial do Ministério da Educação. No entanto, novos estudos que possam acrescer mais informações e trazer amiúde explicações que colaborem para uma maior e melhor interação no ambiente educacional no qual se desenvolve ações cujos atores fazem parte do universo autista, são importantes e necessárias, fato este, que justifica a realização desta pesquisa.

Neste sentido, este artigo tem como objetivo, identificar as principais dificuldades encontradas pela família e por professores, para lidarem com crianças autistas em relação ao processo de ensino - aprendizagem e investigar se as escolas da rede pública de ensino estão preparadas e equipadas para desenvolverem o trabalho específico com crianças/alunos autistas.

\section{O Autismo}

O autismo não é simplesmente uma falta ou dificuldade de comunicação ou até egocentrismo, mas sim, um transtorno que se manifesta durante os três primeiros anos de vida. O autismo se faz presente antes dos três anos de idade e deve ser considerado como uma 
síndrome comportamental que engloba comprometimento nas áreas relacionadas à comunicação, quer seja verbal ou não verbal na interpessoalidade em ações simbólicas, no comportamento geral e no distúrbio do desenvolvimento neuropsicológico (ORRÚ, 2012, p.29).

Segundo a Organização das Nações Unidas (ONU) cerca de 70 milhões de pessoas no mundo são acometidas por esse transtorno.

O Transtorno do Espectro Autista (TEA) é caracterizado por vários sintomas singulares, que afetam a comunicação, a socialização, e o comportamento, interferindo diretamente na interação social, mas uma pessoa com autismo pode sim levar uma vida normal de acordo com o grau do transtorno.

Compreender esse transtorno pode ser relativamente simples quando estamos dispostos a nos colocar no lugar do outro, a buscar a essência mais pura do ser humano e a resgatar a nobreza de realmente conviver com as diferenças. E talvez seja esse o maior de nossos desafios: aceitar o diferente e ter a chance de aprender com ele (SILVA, 2012, p.12):

Os primeiros diagnósticos do autismo surgiram há pouco tempo, por volta da década de 40, onde podemos citar o então psiquiatra Léo Kenner, um austríaco residente nos Estados Unidos, o mesmo dedicou-se aos estudos sobre o autismo e suas manifestações, na época ele achava estranho o comportamento de crianças com características de estereotipias e dificuldades de relacionamento, sendo observado também a ecolalia, (repetição de sons e palavras ouvidas).

A manifestação do autismo pode ser percebida por meio de algumas características quando a criança ainda é muito pequena, e a partir dessa observação pode-se ter um diagnóstico precoce e a busca da adaptação da família e da escola (ORRÚ, 2012: 18-19)

Uma das áreas mais afetadas é a da comunicação, e interpretação de sinais externos, algumas crianças com autismo são bastante sensíveis a alguns sons ou ambientes, e isso se torna perturbador para elas, não esquecendo que o autista tem interesses restritos, ou repetitivos. Neste sentido, poderá se interessar por objetos bem específicos, não tendo flexibilidade em algumas mudanças de rotinas. Identificar uma criança isolada no seu canto, que se balança e geme o tempo todo, como sendo uma criança autista, não é tão fácil. Porem, identificar nuances muito leves de dificuldades sociais em pessoas que não tem nenhum 
Id on Line Revista Multidisciplinar e de Psicoloqia

Id on Line Multidisciplinary Journal and Psycology

diagnostico é bem mais complicado. Entender a fundo os sentimentos e percepções de quem tem esse funcionamento é o primeiro passo para que se possa ajudá-los (SILVA, 2012 p.22).

Na maioria das vezes para a criança autista, o isolamento não é uma opção e sim uma necessidade, pois é como se o contato social se tornasse invasivo. Por isso elas escolhem ficar sozinhas e isso as deixa mas a vontade. Um ponto curioso no dia a dia de uma criança autista é a mudança de comportamento, que se dá durante o final de semana e na segunda feira, não desconsiderando as férias, pois são nesses períodos que os mesmos sofrem com a mudança de rotina, e isso deve ser difícil para a criança e para a família.

Para entendermos melhor sobre as dificuldades encontradas por parte dos familiares de crianças autistas é importante o contato direto e o diálogo com os mesmos, e assim podendo ser observado o processo de adaptação da criança com a própria rotina em casa, que se torna uma tentativa diária com muito esforço e interesse por parte da família. Há dificuldades não só por parte daqueles que a rodeiam no dia a dia, mas também, por parte da escola com relação ao processo de ensino aprendizagem, uma vez que estas precisam ser capacitadas e informadas sobre a inclusão e acompanhamento da criança com, TEA, objetivando que esse processo ocorra sem prejudicar o processo de aprendizagem.

O primeiro passo é o conhecimento. Informações específicas sobre o funcionamento autismo são ferramentas essenciais para orientar o professor no trato com esse aluno e, sobre tudo auxiliá-lo em seu desenvolvimento. Algumas sutilezas, como falar baixo, chamar atenção de forma delicada ou ajudá-lo a entender o conteúdo por meio de figuras ou imagens, são sempre muito bem-vindas ( SILVA, 2012, p.115).

Faz-se necessário que a instituição passe a conhecer a rotina diária da criança dentro e fora do ambiente familiar, só assim será possível uma relação de cooperação a proximidade entre a escola e a família, o que resultará em melhor acompanhamento, assistência e desenvolvimento das ações pedagógicas a serem vivenciadas pela criança.

Quando os professores percebem que as crianças se comportam de maneira estranha, logo procuram conversar com os pais fazendo uma espécie de sondagem na tentativa de captar se estes já perceberam alguma diferença ou não. Trata-se de uma tarefa nem sempre fácil, uma vez que muitos dos pais convidados ao diálogo, simplesmente desconsideram, pois para eles, aceitar que os filhos possam ter algum problema, é algo doloso e preocupante, principalmente se estes filhos nasceram "normais". Observando isso o impacto emocional da 
família e o processo de diagnóstico se tornam bastante difíceis, pois os mesmos ignoram a situação.

Os pais sempre criam expectativas quanto aos filhos, achando que ao crescerem serão pessoas normais, e daí, vem muitas vezes a decepção. Para que esse processo de informação sobre a criança autista se desenvolva sem tanta angustia, a ajuda do psicopedagogo é bastante importante para facilitar um diálogo de entendimento e informação com a família, pois o processo de diagnóstico é bastantemente difícil para os pais, que ficam com sentimento de culpa, pois os mesmos acham que fizeram alguma coisa errada durante o processo de gestação, os pais também sentem um pouco de vergonha com os olhares voltados para o filho que tem autismo, achando muitas vezes que isso não pode ser superado.

Receber o diagnóstico de autismo é sempre impactante para os pais. A partir desse momento, brota um turbilhão de situações e emoções inesperadas no seio familiar: angustias conflitos, frustrações, medos inseguranças. A mãe alvo de muitas criticas na sociedade, é a primeira a se culpar e achar que falhou no processo educacional (SILVA, 2012, p. 94).

Esta realidade evidencia o quanto é necessário que paralelo ao diagnóstico da criança, a família e essencialmente os pais, possam ter um acompanhamento que lhes proporcione esclarecimento e tire suas principais dúvidas sobre a questão. Neste sentido, o psicopedagogo passa a ser uma ponte importante no acompanhamento à criança e sua família, pois o profissional pode se tornar um mediador para um melhor diálogo entre escola e a família.

O papel do psicopedagogo na instituição facilita de forma mais clara a compreensão dos métodos de adaptação na rotina do autista. Esse profissional em parceria com a família, pode diretamente orientar proporcionando através de seus conhecimentos, uma melhor forma de comunicação entre pais e seus filhos autistas, e isso pode acontecer com a ajuda de alguns métodos para que esse diálogo aconteça.

\footnotetext{
O psicopedagogo é como um detetive que busca pistas, procurando selecioná-las, pois algumas podem ser falsas outras irrelevantes, mas sua meta fundamentalmente e investigar todo o processo de aprendizagem levando em consideração a totalidade dos fatores neles envolvidos, para, valendo-se desta investigação, entender a constituição da dificuldade de aprendizagem (SISTO, et al, 2013, p.128 ).
}

Para que o dialogo aconteça de forma simples, podemos citar uma alternativa que possa diretamente servir como opção para facilitar a comunicação do indivíduo autista com as 
Id on Line Revista Multidisciplinar e de Psicoloqia

Id on Line Multidisciplinary Journal and Psycology

pessoas que façam parte de seu ambiente, e essa opção podemos chamar de Tratamento e Educação para Autistas e Crianças com Déficits relacionados a comunicação ou (TEACCH).

\section{Método TEACCH}

O método TEACCH, surgiu em 1966, a partir de uma pesquisa envolvendo a prática psicopedagógica, na Universidade de Carolina do Norte, pelo Dr. Eric Schopler. O mesmo questionava a prática clínica em sua época, que para outros profissionais o autismo tinha como origem uma causa emocional, devendo ser trabalhado pela concepção da psicanálise. Atualmente, é um dos métodos frequentemente utilizados no Brasil e no mundo por instituições que trabalham com autistas e tem seus princípios baseados na teoria comportamental. Ele é considerado um programa educacional e clínico com uma prática psicopedagógica que observa os comportamentos de crianças autistas em distintas situações, de acordo com vários estímulos (ORRÚ, 2012, p.60).

O método TEACCH é utilizado como uma forma de facilitar a comunicação do autista com a família e a escola, principalmente com o profissional que com suas práticas psicopedagógicas possa facilitar esta ponte entre ambos.

\footnotetext{
O programa TEACCH visa indicar, especificar e definir de maneira operacional os comportamentos que devem ser trabalhados. Ele possibilita o desenvolvimento de repertórios que são usados para avaliar os aspectos referentes a interação e organização do comportamento, além do desenvolvimento do indivíduo nos diferentes níveis. O ambiente é totalmente manipulado pelo professor ou pelo profissional que atua com o autista, visando ao desaparecimento ou à redução de comportamentos inadequados a partir de reforço positivo ( ORRÚ, 2012, P.61)
}

\section{Aplicação Do Método TEACCH}

O método TEACCH é baseado e fundamentado na relação de causa e efeito, o mesmo a curto prazo atua facilitando a comunicação que se dá com a apresentação de figuras mostradas para a criança autista, através da identificação dessas figuras, a criança mostrará seu interesse, esse processo é feito de forma individual e o profissional, o professor, indicará 
também o que o aluno deve fazer, essas figuras precisam se mostrar de forma atrativa para que não se torne entediante no processo de comunicação.

No caso dos autistas, as figuras virão representadas com formas de objetos, alimentos, roupas, e até a própria rotina em casa, ocorrendo a ação e reação do aprendente gerando assim, um dialogo entre os comunicantes.

Segundo (ORRÚ, 2012, p.73:74), os principais procedimentos da aplicação e sistematização que costuma ocorrer nesse trabalho, se dão da seguinte forma:

- O profissional sempre procura evitar que o aluno cometa algum erro que lhe reforce o fracasso na atividade;

- Sempre que o aluno queira algo, deverá apresentar ao profissional afigura correspondente; somente após essa conduta, é que obterá a resposta desejada;

- Todas as ações são organizadas pelo profissional para que no decorrer do dia, o aluno possa solicita-lhe algumas delas.

- A ação de o profissional estender a mão é a dica para que o aluno lhe dê a figura esperada

- O treino de figuras é realizado com um grupo de figuras, utilizando uma por vez ( exemplo: grupo de frutas referente a frutas. Faz-se o treino de figura da maçã, posteriormente o da laranja etc;

- Cada aluno deve ter seu próprio sistema individual de comunicação, de forma possa sempre está com ele, e devem ser de preferência, apenas aquelas figuras já dominadas por ele em forma de temas de trabalho.

O resultante da aplicação deste método, vem de forma positiva e a curto prazo, pois facilita a comunicação e independência do autista em seu ambiente, seja ele familiar ou escolar e isso torna satisfatório as interações com as demais pessoas não autistas, havendo uma compreensão por parte dos mesmos.

Na sequencia, as Figuras 1,2,3,4,5,6. Exemplos de material pedagógico trabalhado com crianças autistas, utilizando-se o método TEACCH. 
Id on Line Revista Multidisciplinar e de Psicoloqia

Id on Line Multidisciplinary Journal and Psycology



Figura:1 Representação de frutas

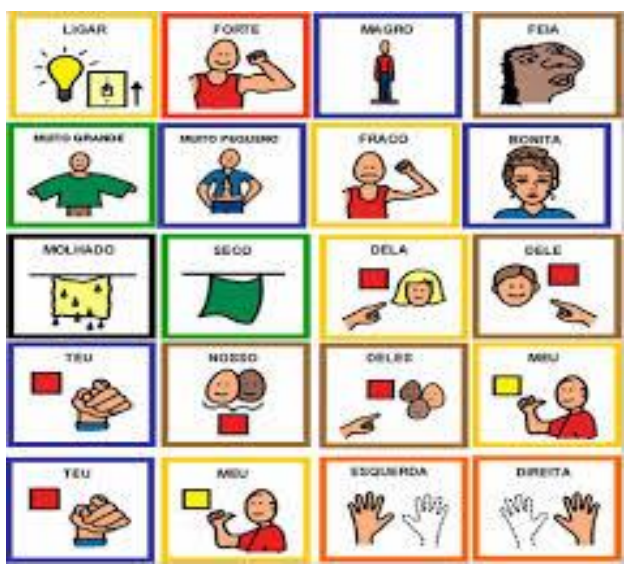

Figura:3 Representação de comunicação

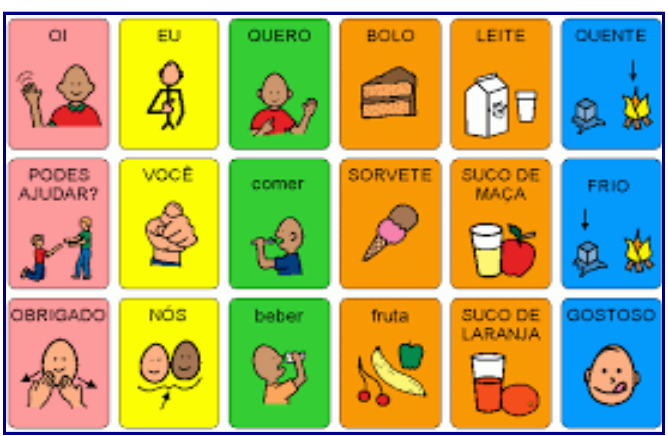

Figura:5 Representação de comunicação



Figura:2 Representação de comunicação


Figura:4 Representação de comunicação

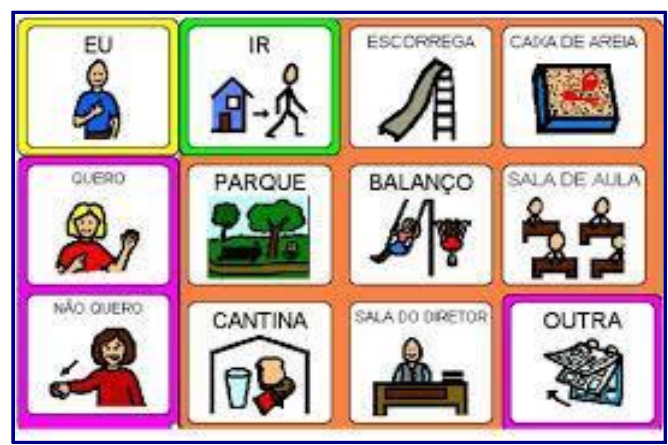

Figura:6 Representação de comunicação 
Id on Line Revista Multidisciplinar e de Psicologia

Id on Line Multidisciplinary Journal and Psycology

\title{
As contribuições de Vigotsk para o trabalho com a criança autista
}

Para enriquecer ainda mais esse artigo, contamos com algumas ideias de Vigotsky e sua contribuição para a educação do indivíduo autista.

\begin{abstract}
Tomando a obra de Vigotsky como referencial teórico para o trabalho com autistas, entendemos que o processo de ensino e aprendizagem desse aluno deve complementar, necessariamente, criteriosa relação entre mediação pedagógica, cotidiano e formação de conceitos, possibilitando o encontro / confronto das experiências cotidianas no contexto em que elas ocorrem para a formação de conceitos, quer seja acadêmicos ou não, em uma maior internalização consciente do que está sendo vivenciado e concebido.( ORRÚ, 2012, p.102)
\end{abstract}

Com base no que foi acrescentado pelo Vigotsky podemos observar que o processo de ensino e aprendizagem do aluno autista se torna um processo cotidiano para o desenvolvimento da linguagem e habilidades que possam facilitar a compreensão de mundo e convivência entre o meio e para que isso aconteça, será indispensável a presença do professor como mediador tornando esse profissional um explorador de conceitos.

As de Vigostsky a cerca da pessoa com necessidades especiais e seu desenvolvimento são significativas com relação a determinação da maneira como essa condição ( "ser deficiente" ) deve ser compreendida e trabalhado no contexto da educação, conferindo-lhe o direito a seu papel ativo na construção de seu desenvolvimento, a partir de sua capacidade individual de apropriar-se e internalizar formas sociais de comportamento como participante de seu processo de conhecimento como sujeito histórico. Somente a tal pessoa passa a ser percebida e compreendida como indivíduo possuidora de diferentes capacidades e potencialidades em emergência, as quais devem ser encorajadas para que se transformem do alicerce do desenvolvimento das funções superiores.( ORRÚ, 2012, p.104).

O individuo independente de sua deficiência, deve ser inserido na sociedade como qualquer outra, usando assim suas habilidades, isso pode acontecer no caso de indivíduos que tenham o considerado autismo leve. A construção da linguagem e o desenvolvimento da aprendizagem de uma pessoa com esse transtorno pode fazer a diferença, mas para isso é preciso comprometimento de um conjunto, em que faça parte a escola, a família, em particular o professor, e o profissional que os acompanham. 
Id on Line Revista Multidisciplinar e de Psicologia

Id on Line Multidisciplinary Journal and Psycology

\section{Metodologia}

Trata-se aqui de uma pesquisa descritiva, a qual quanto ao procedimento adotado se caracteriza como bibliográfica e de abordagem qualitativa. Realizada na APAE da cidade de Juazeiro do Norte, deu-se a partir da aplicação de um questionário que foi respondido por uma profissional responsável pelo trabalho realizado com crianças ali atendidas e por uma psicopedagoga presente na instituição quando da aplicação do referido instrumento. Cada uma delas deu sua contribuição, fornecendo informações necessárias para que a pesquisa acontecesse. Além deste procedimento foi feito também o registro através de algumas fotos mostrando o espaço físico da brinquedoteca, espaço específico para o atendimento às crianças. Cada sessão durava cerca de quarenta minutos e isso foi acompanhado de perto.

\section{A criança autista na Apae de Juazeiro do Norte}

Através de uma visita feita há Associação de Pais e Amigos dos Excepcionais (APAE) na cidade de Juazeiro do Norte - CE, são atendidas crianças com diversas dificuldades, incluindo-se crianças com diagnósticos de autismo e seus variados níveis. A instituição é preparada para receber todas essas crianças, as mesmas ao chegarem lá, passam por uma triagem completa e os responsáveis por esta triagem é um grupo multidisciplinar, a mesma equipe é composta por: Neuropsiquiatra, Geneticista, Psicologo, Clinico geral, Fonoaudiólogo, Assistente social, Terapeuta educacional e Fisioterapeuta e outros profissionais que também dão sua contribuição para que esse trabalho aconteça, são preparados para trabalhar com essas crianças, sendo respeitado o nível de autismo e suas particularidades.

Logo depois do processo de triagem as crianças com autismo começam o atendimento com a psicopedagoga que também os acompanham depois vão para a brinquedoteca sobre a responsabilidade da profissional que faz as atividades de acordo com cada deficiência ou transtorno, incluindo as crianças autistas.

$\mathrm{Na}$ brinquedoteca é feito um trabalho de intervenção, onde a interação é importante para a adaptação da criança com o espaço físico, permitindo-o de se apropriar de objetos que 
lhe interessam ou que chamem sua atenção, feito de forma natural, sem cobranças mas com limitações nos casos de crianças um pouco mais inquietas. De início, a criança mostra seu interesse em algumas atividades, logo depois o profissional tenta estabelecer um jeito de passar segurança para a mesma, sendo assim fica mais fácil e produtiva a sessão, havendo essa conquista, a criança poderá ficar à vontade para brincar sem muitas dificuldades. Quando ela não fala, o profissional tenta estabelecer uma comunicação através da apresentação de figuras ou imagem gestual.

Para trabalhar com as crianças autistas são usadas algumas atividades e objetos que facilitam seu desenvolvimento, começando com a oralidade, socialização, atividades sensoriais exploração aleatória dos brinquedos, dependendo da criança, uns gostam de brinquedos mais simples e outros de brinquedos mais complexos como: prancha de blocos lógicos, e prancha de sequências lógicas.

Quanto aos pais das crianças autistas que fazem parceria com a instituição APAE, são participativos, pois alguns buscam entender como se adaptar ao comportamento de seus filhos com autismo, procurando informações e participando ativamente do desenvolvimento dos filhos autistas. A atividade que vem sendo desenvolvida nessa instituição faz toda diferença, tanto para a criança como também para a família, por isso deve se dar a importância a estas instituições que fazem um belo trabalho para que elas consigam alcançar seus objetivos e para que ajudem outras crianças com suas diversas dificuldades. A visita na APAE foi bastante produtiva, pois nos possibilitou conhecer uma pouco mais dos trabalhos feitos por estes profissionais que são bastante dedicados e eles se sentem felizes por fazerem parte do desenvolvimento da criança autista e das demais pessoas que são atendidas lá.

\section{Considerações Finais}

O autismo é um transtorno que pode atrapalhar o desenvolvimento e a aprendizagem de uma criança, assim como se torna um obstáculo para a família e a escola adaptar-se com a rotina da criança com autismo. Mesmo com o surgimento de estudos, desde a década de 40, torna-se ainda difícil diagnosticar esse transtorno. Para os pais é sempre uma nova experiência diária e uma nova descoberta, é importante que os profissionais uma vez envolvidos com o 
processo de ensino e aprendizagem estejam comprometidos a dá sua contribuição para o avanço de crianças autistas.

O psicopedagogo neste contexto tem grande importância, pois representa uma rede de conexão entre a família e escola, para que a criança autista através dos métodos utilizados se torne um indivíduo autônomo, dependendo do grau de autismo, facilitando assim sua comunicação com o mundo e possibilitando sua aprendizagem.

\section{Referências}

ORRÚ, Sílvia Ester. Autismo, linguagem e educação: interação social no cotidiano escolar. Rio de Janeiro: Wak ed, 2012.

SILVA, Ana Beatriz Barbosa et al. Mundo singular: entenda o autismo. Rio de Janeiro: Objetiva, 2012.

SISTO, Fermino Fernandes et al. Atuação psicopedagógica e aprendizagem escolar. Petrópolis, RJ , Vozes, 2013.

\section{Anexos}

\section{Questionário da Pesquisa}

1. Quais as atividades que podem ser trabalhadas com crianças autistas?

2. Quantas crianças com autismo são atendidas na instituição?

3. Como se dá a intervenção educacional?

4. Como se dá a interação social da criança?

5. Como se dá a forma de aprendizagem em sala de aula?

6. Como se dá a interação, família e escola?

7. Os profissionais são preparados, para o atendimento das crianças com autismo?

8. Quais os métodos de adaptação e rotinas usados para as crianças autistas?

9. Quando as crianças chegam para fazer parte da instituição, quais são os procedimentos? 
Id on Line Revista Multidisciplinar e de Psicoloqia

Id on Line Multidisciplinary Journal and Psycology

10. Na instituição há crianças que não falam? Se tem, quais são os procedimentos para que haja a comunicação?

11. O aluno frequenta a escola regular?

12. Na escola o profissional cuidador está preparado para acompanhar essa criança?

13. Quais as dificuldades enfrentadas pela família no dia a dia, para lidar com a criança autista?

14. Os pais conseguem ter uma rotina em casa, com a criança? Como se dá essa rotina?

15. Quais as dificuldades enfrentadas pela instituição, para lidar com uma criança autista?

\section{Brinquedoteca onde são realizadas as atividades de intervenção}
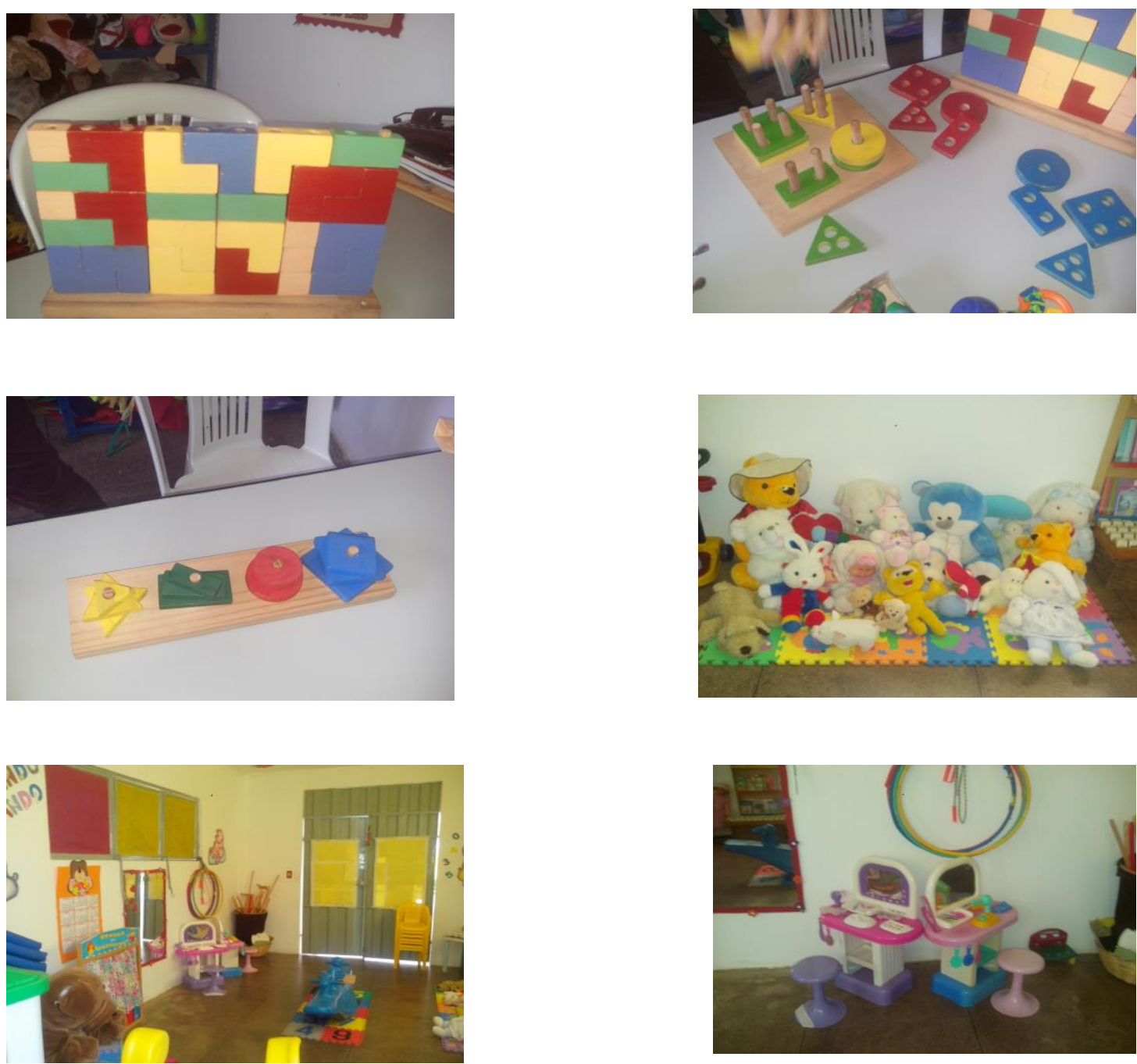
Id on Line Revista Multidisciplinar e de Psicoloqia

Id on Line Multidisciplinary Journal and Psycology
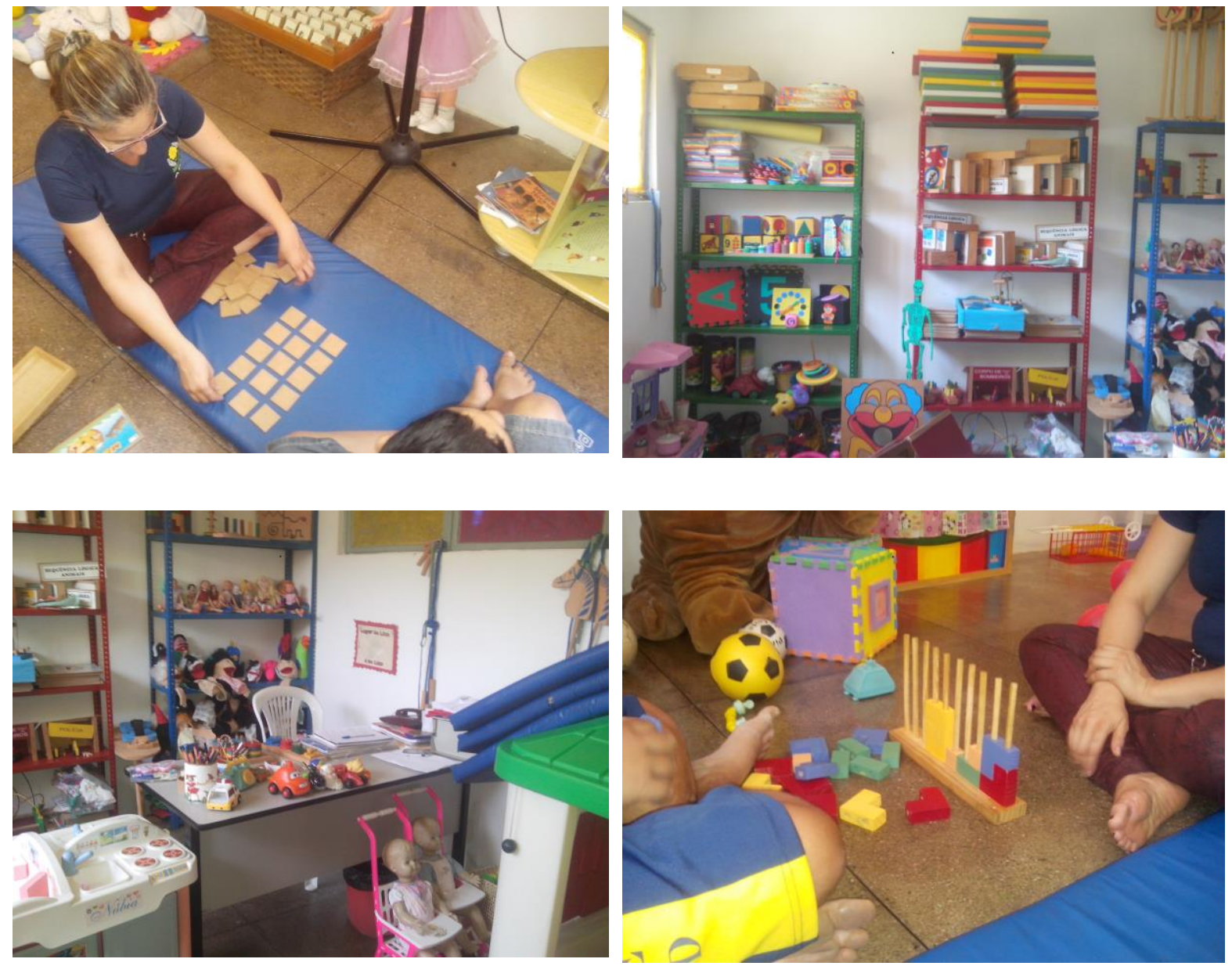

\section{Como citar este artigo (Formato ABNT):}

CARVALHO, C.R.S. Crianças Autistas e o Processo de Ensino e Aprendizagem: desafio para pais e professores. Id on Line Revista Multidisciplinar e de Psicologia, Set-Out de 2016, vol.10, n.31, Supl 2, p. 291-304. ISSN 1981-1179.

Recebido: $12 / 09 / 2016$

Aceito: 22/09/2016 